\title{
Review
}

\section{Against autonomy: Justifying coercive paternalism}

\author{
Sarah Conly \\ Cambridge University Press, New York, 2013, 206 pp., \$32.99 \\ ISBN: 978-1107024847
}

Contemporary Political Theory (2014) 13, e15-e17. doi:10.1057/cpt.2013.44

Against Autonomy: Justifying Coercive Paternalism is a provocative book that asks important questions. Why do we value autonomy? Should we value it less? Sarah Conly provides a thoughtful analysis of these questions in making her argument that coercive paternalism is justified in more situations than commonly thought. She argues for a means-only paternalism in which the government would implement paternalistic practices so that individuals can achieve the goals they set out for themselves. Government would not be in the business of telling us what our goals should be. This form of paternalism is justified largely because we "now know that we are intractably irrational and that this can't be rectified by simple care and introspection' (p. 7). We want to lose weight, but we eat too much. We do not want to file for bankruptcy, but we take on too much debt. Experts can help us achieve our goals. For example, they could limit portion sizes in restaurants, ban trans fats and prevent us from taking out the loan we likely will not be able to repay.

Conly's text engages with a range of important philosophical questions. She argues, for example, that we value individuality more than we should and that the paternalistic regulations she favors would not unduly threaten privacy. She also argues that paternalistic laws would not result in inauthentic selves who have no capacity for critical reflection. Such laws may tell us 'that we need help in some decision making circumstances', but this just 'help[s] people know what they are capable of and what they are not capable of', which in turn 'helps us recognize our true options' (p. 93).

Despite the range of issues she addresses, Conly fails to consider some of the most trenchant critiques of her position. One major problem is that she does not grapple with the substantial literature that critiques autonomy from critical and feminist perspectives. She has a passing reference to the fact that 'Marx, Freud, and the philosophical insights of feminism' have resulted in a 'revised ... view of human agency' (p. 7). Conly does not, however, seriously consider what those critiques might mean for her project. Had she thoroughly examined feminist scholarship on

(C) 2014 Macmillan Publishers Ltd. 1470-8914 Contemporary Political Theory Vol. 13, 4, e15-e17 
autonomy, for example, she would have found a deep distrust of the concept because it has often been used to obscure the social context and relations of power in which decisions are made and desires formed. Instead of using such insights as the basis for a treatise against autonomy, Conly makes the very mistakes that defenders of autonomy often make - she pays little attention to social forces and context. Her hyperfocus on the individual makes it appear as though individual irrationality is the primary obstacle to the achievement of our goals.

Although this oversight runs throughout Against Autonomy, it is most glaring in the book's penultimate chapter in which Conly applies her justification for coercive paternalism to a few policy examples. Her favored examples are those dealing with health, where her assumption that we have straightforward and widely shared goals (to be healthy) seems most plausible. To illustrate some of the issues that arise from Conly's framework, let us examine her argument regarding limiting portion size at restaurants. She argues that such a limit is justifiable because it fulfills her four criteria: it promotes a long-term goal, it would likely be an effective regulation, the benefits appear to be worth the costs and it is perhaps the most efficient way to reduce the amount of fattening food that people eat (pp. 162-169).

In addition to helping us achieve our goal of health, Conly claims that portion size regulations would also allow people to achieve their alleged long-term goal of conforming 'to the popular cultural standard of attractiveness' (p. 164). In Conly's framework, then, the problem to be solved is not oppressive beauty standards, but individuals' purportedly poor decision making that keeps them from meeting those standards. In this instance, she seems to equate rationality with conforming to social norms, which should raise red flags. In this case, the conflation of rationality with social norms leads her to ignore the possibility that some individuals would deliberately try to subvert dominant beauty standards by, for example, celebrating bodies that do not adhere to the cultural ideal. Because she ignores this possibility and the social context within which people make decisions and form their desires, her solution is not to change norms, but is rather to invoke paternalistic legislation that would help us adhere to even quite problematic social norms.

Conly's primary focus on the individual leads her to ignore other important aspects of the circumstances in which people make decisions. In the case of portion size limits - which she argues would help us achieve our presumed goal of skinnier, healthier bodies - Conly assumes that body size is largely under individual control. If you fail to have a thin body, it must be because you make bad decisions to eat fatty food. This ignores the scientific research that is increasingly showing that body size is more complex than that and is affected by everything from the bacteria in our gut to our genes. Conly's hyperfocus on the individual also leads her to overlook the possibility that the food industry is partially to be blamed for our health. Although she acknowledges that fast food restaurants have slowly increased portion sizes to increase profit, she does not place blame on such restaurants for health outcomes. In the context of personal debt, Conly makes similar mistakes in her reasoning. 
Although noting that bank deregulation is part of what led to the mortgage crisis, Conly appears to place the responsibility for bad loans primarily on individuals' irrational decisions, not banks' coercive practices. She thus ignores the role that industry manipulation and coercion play in individuals' decision making.

Once the broader context is properly understood, Conly's proposed laws look less like straightforward paternalism and more like regulations to curb manipulative or coercive industry practices that also, and sometimes only in an insignificant way, restrict what individuals can do. Another way to think about portion size regulations is that they substitute a manipulative practice (fast food restaurants deciding how many fries you really want) for a more benevolent one (the government deciding that a smaller size is better for you) that is largely meant as a restriction on what restaurants can do. After all, as you can still get as many fries as you want (you can get two orders instead of one), it is not all that clear that it is much of an affront to your autonomy at all. Of course, the line between preventing manipulative or coercive practices and engaging in paternalism can be quite blurry. That line is worthy of critical examination. Instead of engaging in such an examination, though, Conly asserts that the problem is primarily individual irrationality and poor decision making.

In the end, Conly's conclusions, if not all of her arguments, are not as controversial as they first appear. Moreover, her coercive paternalism is not so different from liberal theory's standard perspective on autonomy. In fact, coercive paternalism often functions as the other side of autonomy. Only those who have been deemed capable of rationality have historically been granted autonomy. For those whose decisions and decision-making capacity are not trusted - which tend to be those on the margins of society - paternalism has often seemed justified. Conly would extend the ambit of this paternalism to include, in limited circumstances, many more people. Yet, the ways in which she would allow experts to determine how we can best achieve our ends are not all that different from what traditional autonomy theory would seem to justify. Conly's inattention to context and history also means that she does not fully consider that, in practice, expertise and coercive paternalism are often used to reinforce social hierarchies. She does not consider the way in which expertise is often used to depoliticize the very relations of power that are at the root of the social problems Conly wants to correct by letting experts guide us to rationality. 